\title{
Norepinephrine transporter (NET) is expressed in cardiac sympa- thetic ganglia of adult rat
}

\author{
LI HE ${ }^{1,2}$, Sun Kai MA ${ }^{1}$, Xiao Ping HU ${ }^{3}$, Gou Yuan ZHANG ${ }^{2}$, Jian FEI ${ }^{1, *}$ \\ 1 Institute of Biochemistry and Cell Biology, Shanghai Institutes for Biological Sciences, Chinese Academy of \\ Sciences, Shanghai 200031, China \\ 2 Cardiovascular Division of Changzheng Hospital, Shanghai 200003, China E mail: h-li@hotmail.com \\ 3Pathological Division of Pu Nan Hospital, Shanghai 200125, China
}

\begin{abstract}
The sympathetic nervous system plays a cardinal role in regulating cardiac function through releasing the neurotransmitter norepinephrine (NE). In comparison with central nervous system, the molecular mechanism of NE uptake in myocardium is not clear. In present study, we proved that in rat the CNS type of NE transporter (NET) was also expressed in middle cervical-stellate ganglion complex (MC-SG complex) which is considered to control the activity of heart, but not expressed in myocardium. The results also showed that NET expression level in right ganglion was significantly higher than in the left, rendering the greater capacity of $\mathrm{NE}$ uptake in right ventricle, a fact which may contribute to the maintenance of right ventricular function under pathologic state.
\end{abstract}

Key words: Norepinephrine transporter; gene expression; cardiac sympathetic ganglion, rat.

\section{INTRODUCTION}

The sympathetic nervous system (SNS) plays an important role in regulating cardiac function in both health and disease through releasing neurotransmitter norepinephrine (NE). In central nervous system (CNS), the neurotransmission of NE is terminated through reuptake of released neurotransmitter by $\mathrm{Na}^{+}, \mathrm{Cl}^{-}$dependent norepinephrine transporter (NET) on pre-synaptic membrane[1], [2]. Although the NE uptake was well studied in heart, but the molecular basis for that is still less clear[3-5]. Ungerer et.al indicated that they could not detect any specific mRNA of NET in the myocardium investigated [6]. They postulated that somehow norepinephrine transporter protein might be synthesized in neuronal cell situated away from the heart and then transported into the cardiac nerve ending via axon

\footnotetext{
* Corresponding author, E mail: feijian@sunm.shenc.ac.cn Received May-30-2001 Revised Aug-15-2001 Accepted Aug-252001
}

transport. In this study, we proved that NET is expressed in middle cervical-stellate ganglion complex (MC-SG complex) of rat and also showed that different NET expression levels were existed between left and right ganglion.

\section{MATERIALS AND METHODS}

\section{Animals}

Male Sprague-Dawley rats at $8 \mathrm{w}$ of age and weighing 180-200 $\mathrm{g}$ were used. After acclimatization period rats were sacrificed by decapitation and isolated the MC-SG complex of both side and left ventricular myocardium quickly. They were immediately frozen in liquid nitrogen and stored at $-70 \mathrm{oC}$ for use.

\section{$R N A$ extraction and $c D N A$ preparation}

Total RNA was extracted from the MC-SG complexes and left ventricular myocardium using TRIzol (GIBCO). After the treatment of final RNA aliquots with DNase I to eliminate contamination of genomic DNA, $1 \mu \mathrm{g}$ of total RNA was used for reverse transcription (RT) into cDNA with M-MLV (GIBCO) according to the manufacturer using random primer. 
NET is expressed in cardiac sympathetic system

PCR cloning of rat NET

PCR primers for rat NET are as follows: 5' -CTCAA GGAGG CCACG GTATG GATCG- 3' (for the sense primer, gene bank accession number: Y13223.1, the sequence position is from 904 to 928) and 5' -ACCTG GAAGT CATCA GCCAG TCCGG-3' (for the antisense primer, gene bank accession number: Y13223. 1 , from 1286 to 1310). The PCR reaction was performed as 35 cycles at $94^{\circ} \mathrm{C}$ for $1 \mathrm{~min}, 65^{\circ} \mathrm{C}$ for $1 \mathrm{~min}$, and $72^{\circ} \mathrm{C}$ for $3 \mathrm{~min}$. The products were analyzed on $1.8 \%$ agarose gel. The DNA band was purified from gel and then cloned into pBluscript KS and sequenced by the dideoxynucleotide method.

For quantitative analysis of NET gene expression by RTPCR, the expression of $\beta$-actin was used as the reference for normalization. The primers for RT-PCR of $\beta$-actin are 5' TCATG AAGTG TGACG TTGAC ATCCG TAAAG-3' (for the sense primer, gene bank accession number: V01217.1, sequence position is from 2727 to 2756 ) and 5'-CCTAG AAGCA TTTGC GGTGC ACGAT GGAGG-3' (for the antisence primer, from 3106 to3135).

\section{Northern blot analysis of NET}

The PCR product of NET was labeled with ${ }^{32}$ p-dATP and used as probe for Northern blot. Twelve mg of total RNA from the ganglia $(n=5)$ and myocardium of $\operatorname{LV}(n=5)$ were run on $1 \%$ agarose-formaldehyde gel and transferred to a Hybond-N membrane (Amersham Co). Pre-hybridization and hybridization were carried out according to standard method with the probe of NET. After hybridization, the membrane was washed twice in $2 \times \mathrm{SSC}$ at room temperature, once in $1 \times \mathrm{SSC}$ at $42^{\circ} \mathrm{C}$ for $20 \mathrm{~min}$, then 20 min in $0.1 \times \mathrm{SSC}$ at $65^{\circ} \mathrm{C}$. After autoradiography exposure, the membranes were stripped and re-hybridized with $32 \mathrm{P}$ labeled b- actin cDNA probe. Hybridization signal of specific band of NET was measured by densitometry, and was normalized by the corresponding hybridization signal of $\beta$ actin to correct the differences in loading and transfer.

\section{RESULTS AND DISCUSSION}

Neurotransmitter transporters play an important role in controlling of neural signal transmission, dysfunction in expression of neurotransmitter transporter genes may cause different diseases[7-9]. To determine if there is NET expressed in cardiac sympathetic system, RT-PCR was carried out from total RNA of rat myocardium and cardiac sympathetic ganglia. Fig 1 showed that PCR product in expected size was obtained from MC-SG amplified with the primers of NET. The product was gel purified and cloned and partially sequenced. It was identical to the expected sequence in NET (sequence data not shown). In contrast, no specific band could be amplified from rat myocardium $(n=3$ each), although the b-actin as the control was equally present in all
cDNAs.

To determine whether there is difference in NET mRNA expression in left and right MC-SG, Northern blot was performed. Fig 2 showed that NET mRNA level in the right was 2.2 fold higher than that in the left $(p=0.01, n=5)$.

SNS regulates the function of innervated effector organs through releasing neurotransmitter $\mathrm{NE}$ [10]. The released transmitter in the cleft binds receptors on the postsynaptic membrane through diffusion, by which the signal is transmitted. After that, NE must be rapidly eliminated from the synaptic cleft. In CNS, this is done by plasma membrane protein of sodium-dependent NE transporter (NET) which has been cloned before[11]. However, the NE uptake mechanism in cardiac system is not clear. Recently Ungerer and co-workers reported that they could not detect NET mRNA expressed in the myocardium. Therefore, it was assumed that

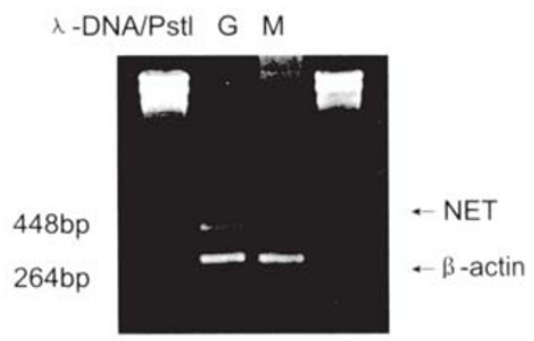

Fig 1. RT-PCR analysis showing NET expression in MC-SG (G) but not in myocardium(M)

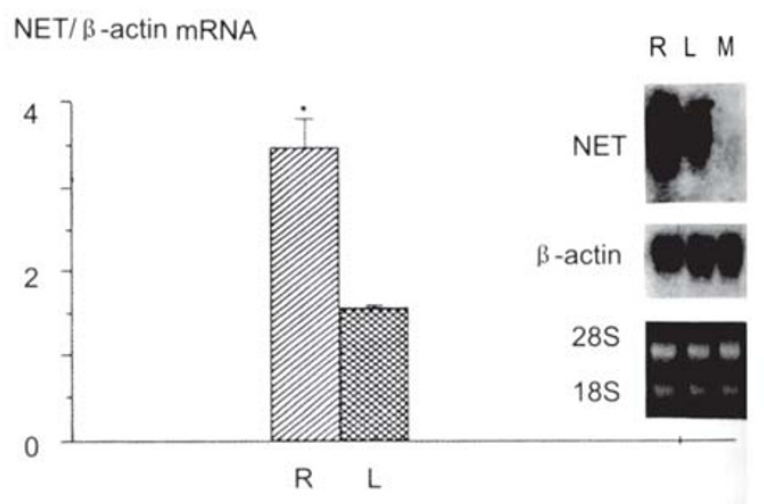

Fig 2. NET mRNA levels in right(R) and left(L) cardiac sympathetic ganglia determined by Northern hybridization analysis. The ratios are expressed as ratio to beta actin mRNA. ${ }^{*} \mathrm{P}<0.05$, NET mRNA levels in the right ganglia vs. the left. No detectable NET expression in myocardium of left ventricle (M). 
NET mRNA might be expressed, if there is any, in the neuronal cell soma, which is located a considerable distance from the heart[6]. Subsequently, Matsuoka et al also showed high levels of NET mRNA in the cultured superior cervical ganglia (SCG)[12]. Following their works, we investigated the NET expression in cardiac sympathetic nervous system, the experiments clearly showed that NET mRNA expression is present in the MC-SG complex but not in the myocardium. This result supports the contention that NE uptake system in myocardium is formed by NET which is transported from a distance from the heart and also indicates that SNS in heart shares the same mechanism of $\mathrm{NE}$ concentration regulation with CNS .This information may be useful for development of new drugs targeting NET to treatment of heart disease.

The cardiac sympathetic ganglia of rat are MCSG. This was proved by retrograde tracer experiments. The innervation is primarily ipsilateral(approximately 60\%) with significant contralateral contributions[5], [13]. Previous studies still suggested that right and left cardiac sympathetic nerves may have different and specific effects on cardaic excitability[14], [15]. The postganglionic fibers from the right stellate ganglia(RSG) appear to play more important role than those from the left stellate ganglia (LSG) in maintaining contractile force, especially heart rate,. The apparent attenuation of heartbeat irregularity was observed when right stellate ganglia (RSG) innervation is interrupted, but the left stellate ganglionectomy (LSG), which is considered to affect cardiac inotropism rather than chronotropism, had no effect on cardiac interval irregularity[16]. MIBG (metaiodobenzylguanidine) is thought to share the same uptake, storage, and release mechanisms as $\mathrm{NE}$ in the adrenergic nerve terminals[17]. Nozawa and colleagues reported that MIBG uptake and accumulation was greater in the right ventricular myocardium than in the left in rats[3]. In our experiment, it was shown that the NET expression is higher in right cardiac sympathetic ganglia of adult rats. This result provides a molecular biological evidence to explain the difference between RSG and LSG and for the greater capacity of NE uptake of the right vs the left myocardium.

\section{ACKNOWLEDGEMENT}

This study was supported by Postdoctoral Fellow Foundation of the Science and Technology Committee of Shanghai (grant No. 98-10), grant from Special Funds for Major State Basic Research of China (G19990539).

\section{REFERENCES}

[1] Amara S. Neurotransmitter transporters: recent progress. Ann Rev Neurosci 1993; 16:73-93.

[2] Barkely RD, De Felice LJ, Hartzell HC. Molecular physiology of norepinephrine and serotonin transporters. J Exp Biol 1994; 196:263-81.

[3] Nozawa T, Igawa A, Yoshida N, Maeda M, Inoue M, Yamamura Y, Asanoi H, Inoue H. Dual-tracer assessment of coupling between cardiac sympathetic neuronal function and downregulation of b-receptors during development of hypertensive heart failure of rats. Circ Res 1998; 97:2359-67.

[4] Ganguly PK, Dhalla KS, Shao QM, Beamish RE, Dhalla NS. Differential changes in sympathetic activity in left and right ventricles in congestive heart failure after myocardial infarction. Am Heart J 1997; 133:340-5.

[5] Pardini BJ, Lund DD, Schmid PG. Innervation patterns of the middle cervical stellate ganglion complex in the rat. Neurosci Letter 1990; 117:300-6.

[6] Ungerer M,Chlistalla A,Richardt G. 1996.Upregulation of cardiac uptake1 carrier in ischemic and nonischemic rat heart. Circ Res 1996; 78:1037-43.

[7] MA Ying Hua, Jia Hua HU, Xiao Gang ZHOU, Zhen Tong MEI, Jian FEI, Li He GUO. g-Aminobutyric Acid Transporter (GAT1) Overexpression in Mouse Affects the Testicular Morphology. Cell Research 2000; 10:59-69.

[8] MA Ying Hua, Jia Hua HU, Xiao Gang ZHOU, Ruo Wang ZENG, Zhen Tong MEI, Jian FEI, Li He GUO. Transgenic mice overexpressing g-aminobutyric acid transporter subtype I develop obesity. Cell Research 2000; 10:303-10.

[9] MA Ying Hua, Wen Juan ZHAO, Jia Hua HU, Jian FEI, Ying HU, Xiao Gang ZHOU, Zhen Tong MEI, Li He GUO. Overexpression of g-aminobutyric acid transporter subtype I leads to susceptibility to kainic acid induced-seizure in transgenic mice. Cell Research 2001; 11(1):61-7.

[10] Esler M, Jennings G, Lambert G, Meredith I, Horne M, Eisenhofer Gl. Overflow of catecholamine neurotransmitters to the circulation: source, fate, an dfunctions. Physiol Rev 1990; 70:963-85.

[11] Pacholczyk T, Blakely R, Amara S. Expression cloning of a cocaine- and antidepressant-sensitive human noradrenaline transporter. Nature 1991; 350:350-4.

[12] Matsuoka I, Kumagai M, Kurihara K. Differential and coordinated regulation of expression of norepinephrine transporter in cetecholaminergic cells in culture. Brain Res 1997; 776:181-8.

[13] Pardini BJ, Lund DD, Schmid PG. Orgnization of the sympathetic postganglionic innervation of the rat heart. J Auton Nerv Syst 1989; 28:193-202.

[14] Schwartz PJ, Snebold NG, Brown AM. Effects of unilat- 
NET is expressed in cardiac sympathetic system

eral cardiac sympathetic denevervation on the ventricular fibrillation threshold.Am J Cardiol 1976; 37:103440.

[15] Schwartz PJ, Stone HL, Brown AM. Effects of unilateral stellate ganglion blockade on the arrhythmias associated with coronary occlusion. Am Heart J 1976; 92:589-99.

[16] Lipsitz LA, Pincus SM, Morin RJ, Tong S, Eberle LP, Gootman PM. Preliminary evidence for the evolution in complexity of heart rate dynamics during autonomic maturation in neonatal swine. J Auton Nerv Syst 1997; 65:1-9.

[17] Glowniak JV, Kilty JE, Amara SG, Hoffman BJ, Turner FE. Evaluation of metaiodo- benzylguanidine uptake by the norepinephrine,dopamine and serotonin transporters. J Nucl Med 1993; 34:1140-6. 